\title{
Targeted Delivery of Antisense Oligonucleotides by Molecular Conjugates
}

\author{
Bruce A. Bunnell, ${ }^{1}$ Frederick K. Askari, ${ }^{1}$ and James M. Wilson ${ }^{1-3}$ \\ ${ }^{1}$ Departments of Intemal Medicine, ${ }^{2}$ Biological Chemistry, and ${ }^{3}$ Howard Hughes Medical Instifute, \\ University of Michigan Medical Center, Ann Arbor, Michigan 48109
}

Received 31 August 1992

\begin{abstract}
Antisense oligonucleotides efficiently inhibit gene expression in vitro; however, the successful therapeutic application of this technology in vivo will require the development of improved delivery systems. In this report we describe a technique that efficiently delivers antisense oligonucleotides into cells using molecular conjugates. This technique, which was initially developed for the delivery of eukaryotic genes, is based on the construction of DNA-protein complexes that are recognized by the liver-specific asialoglycoprotein receptor. Binding of poly( $L$-lysine)asialoorosomucoid (AsOR) protein conjugates with phosphorothioate antisense oligonucleotides to chloramphenicol acetyltransferase (CAT) led to the formation of 50 - to $150 \mathrm{-nm}$ toroids. Exposure of the antisense molecular complexes (3 $\mu M$ oligonucleotide) to NIH $3 T 3$ cells genetically modified to express both the AsOR receptor and CAT, inhibited CAT expression by $54 \%$, which was completely blocked by excess AsOR. Equivalent inhibition of CAT activity with purified oligonucleotide alone was observed at a $30 \mu M$ concentration. Furthermore, examination of the cells using indirect immunofluorescence for the presence of $C A T$ protein showed $28 \%$ of cells exposed to the molecular conjugates lacked any detectable CAT enzyme. Cells exposed to oligonucleotide alone showed a highly variable staining pattern, and only a few of the cells were completely void of CAT protein. Together these data demonstrate that molecular conjugates provide a highly specific and efficient system for the delivery of antisense oligonucleotides.
\end{abstract}

\section{INTRODUCTION}

The existence of naturally occurring antisense RNA molecules has been described in prokaryotes and more recently eukaryotes $(1,2)$. It is believed that these RNAs directly inhibit gene expression by hybridizing to the complementary sense sequences. Since their discovery, there has been intense interest in developing antisense nucleic acid technology for use as therapeutic agents against viruses and oncogenes.

The ability to synthetically produce antisense sequences in the form of oligonucle- otides has greatly facilitated the development of antisense reagents because they can be produced in large quantities and can be designed to exacting specifications. Experiments performed with standard phosphodiester-linked antisense oligonucleotides have met with varying degrees of success $(3-6)$. The major limitation has been the development of methods for efficient delivery of oligonucleotides into appropriate compartments of the cell. The data from such experiments indicate that short oligonucleotides are transported into the cell by an active transport mechanism and are capable 
of inhibiting gene expression $(7,8)$. The in vivo applications of phosphodiester based oligonucleotides have been disappointing due to their sensitivity to nucleases, as well as very low efficiency of transport across the cell membrane.

In an attempt to alleviate the transport and nuclease sensitivity problems, oligonucleotides with nonionic internucleotide linkages have been developed (9). Several types of modified phosphate linkages have been generated, including phosphothioesters, phosphoaramidates, and methyl phosphonates (10-13). A significant advantage of the modified oligonucleotides is that they have an extended half-life within the cell because the modified internucleotide linkages make them highly resistant to nucleases $(14,15)$. The chemically modified oligonucleotides are also nonionic molecules that may have enhanced permeability to the cell membrane (16) and may have enhanced binding activities for target sequences under physiologic conditions (17). Extensive investigation into the use of these modified oligonucleotides as potential agents against viral infections both in vitro and in vivo has revealed them to be highly effective at specifically blocking viral replication without being toxic to cells (18-20). Although the modified oligonucleotides have shown great potential for use as therapeutic molecules, they have not become clinically practical because of the large quantities of oligonucleotide necessary to achieve a significant reduction in gene expression and lack of specificity in terms of delivery in vivo. Currently, there are no methods to efficiently and specifically deliver large quantities of oligonucleotide to a high proportion of eukaryotic cells in vitro or in vivo.

Molecular conjugates, a soluble DNA carrier system, were initially developed as a method for targeting the transfection of genes to specific cells $(21,22)$. The conjugates utilize receptor-mediated endocytotic mechanisms for delivering genes into cells. The principle behind plasmid-based molecu- lar conjugates is that the negatively charged DNA will electrostatically interact with positively charged polylysine to form compact structures called toroids. By covalently linking a specific receptor ligand, such as asialoorosomucoid or transferrin, to the polylysine to form DNA-protein complexes, it has been possible to target cell-specific surface receptors and transfect plasmid DNA into cells (23). Recently, functional conjugates were generated to cell surface receptors for asialoorosomucoid (AsOR) and transferrin $(24,25)$. Using the AsOR molecular conjugates, hepatocyte-targeted gene delivery has been studied in vivo using several different animal models, including the Watanabe heritable hyperlipidemic rabbit (26).

In the present study, AsOR molecular conjugates were investigated as a potential delivery system for antisense oligonucleotides. The study consisted of forming DNAprotein complexes between phosphorothioate antisense oligonucleotides directed toward chloramphenicol acetyltransferase (CAT) and the AsOR-polylysine conjugates. Electron microscopy revealed that the molecular conjugates formed classic toroidal structures. The antisense molecular conjugates were then analyzed for their ability to inhibit CAT activity in stably transfected cells using indirect immunofluorescence and enzymatic assays. The data presented here demonstrate that formation of molecular conjugates with an antisense oligonucleotide provides a highly efficient delivery system for large quantities of oligonucleotide to a high proportion of target cells. The use of molecular conjugates for the delivery of oligonucleotides may thus prove to be an effective approach for the development of antisense oligonucleotides as potential therapeutic agents.

\section{MATERIALS AND METHODS}

Preparation of Targetable Conjugate. Orosomucoid (Sigma) was enzymatically treated for $30 \mathrm{~h}$ with neuraminidase derived from 
Vibrio cholerae (Boehringer Mannheim Biochemical) to cleave terminal sialic acid groups, thus generating AsOR, which was cross-linked at $\mathrm{pH} 8.0$ to poly-L-lysine $\left(\mathrm{MW}_{\text {vis }}=21.7 \mathrm{kDa}\right.$; Sigma $)$ at a molar ratio of 1.3:1 for $15 \mathrm{~h}$ in the presence of a molar excess of 1-ethyl-3-(3-dimethylaminopropyl) carbodimide (EDC; Pierce Chemical Co.). AsOR-poly(L-lysine) conjugate was purified by ion-exchange chromatography (CM-Bio Gel A; Bio-Rad). Fractions containing conjugate were identified by their OD at $280_{\mathrm{nm}}$, lyophylized, and resuspended in $0.15 \mathrm{M}$ $\mathrm{NaCl}, 20 \mathrm{mM}$ HEPES, $\mathrm{pH}$ 7.8. A more detailed description of the synthesis and purification of conjugate, as well as the formation of complex, will be provided elsewhere.

Oligonucleotides, Plasmids, and Cell Lines. An 18-base phosphorothioate oligonucleotide with the sequence: $5^{\prime}$-AGTGATTTTTTTCTCCAT-3', which is complementary to the translational initiation methionine of the CAT RNA, was synthesized. A control phosphorothioate oligonucleotide, which is complementary to the translational initiation methionine of the S-gene of hepatitis $B$ virus, was also generated with the sequence: $5^{\prime}$-TGATGTGATGTTCTCCAT3'. Both oligonucleotides were synthesized on an Applied Biosystems model 391B DNA synthesizer (DNA Synthesis Core). Fulllength oligonucleotides were purified by UV-shadowing following electrophoresis on a $15 \%$ polyacrylamide $-7 \mathrm{M}$ urea gel. Purified oligonucleotides were resuspended in $10 \mathrm{mM}$ Tris- $\mathrm{HCl}, 1 \mathrm{mM}$ EDTA, $\mathrm{pH}$ 7.4. $3 \mathrm{~T} 3$ fibroblasts transduced with the cDNAs for the H1 and $\mathrm{H} 2 \mathrm{~b}$ domains of the asialoglycoprotein receptor ( 171 cells) were graciously provided by Drs. Michael Shia and Harvey Lodish (27). An [125I]AsOR degradation assay was performed to document the persistent expression of functional asialoglycoprotein receptor. The cells were maintained in culture in DMEM, $10 \%$ calf serum, $1 \%$ penicillinstreptomycin at $37^{\circ} \mathrm{C}$ in $5 \% \mathrm{CO}_{2}$. The CAT clonal cell lines were produced by transfec- tion of 171 cells with the plasmid pRSV-CAT and $\mathrm{pSV}_{2}$ his (10:1 ratio) and selected in DMEM, $10 \%$ heat-inactivated calf-serum, $1 \%$ penicillin-streptomycin, and $0.12 \mathrm{mM}$ histidinol (28). Individual clonal cell lines were screened for CAT enzymatic activity by enzyme assay and indirect immunofluorescence. CAT-producing cell lines were then rescreened for retention of the asialoorosomucoid receptor by molecular conjugatemediated delivery of $\beta$-actin nuclear-targeted lac $Z$ ( $\beta A$-ntlacZ) plasmid DNA. Evidence for the receptor-mediated transfection was provided by staining the cells for $\beta$-galactosidase activity as previously described (29).

Generation of Molecular ConjugateOligonucleotide Complexes. To determine the ratio of conjugate to oligonucleotide required for the formation of a soluble complex, an agarose-gel retardation assay was performed. For this assay, $100 \mathrm{ng}$ of the 18 -mer was end-labeled with $\left[\gamma^{32}\right.$ P]ATP (3000 Ci/mmol, NEN-DuPont) using T4 polynucleotide kinase (Boehringer-Mannheim Biochemical). Labeled oligo (1.0 ng) was mixed with excess unlabeled oligonucleotide (99 $\mathrm{ng}$ ) in order to perform the assay. The total amount of oligonucleotide remained constant in all samples. The oligonucleotide was mixed with increasing amounts of conjugate in the following ratios $0: 1,0.1: 1$, $0.5: 1,1: 1,2: 1,5: 1$, and $10: 1$. The DNAconjugate suspension was incubated for 30 $\min$ at room temperature. The reaction products were then analyzed on a $1.5 \%$ agarose gel. The gel was electrophoresed at $50 \mathrm{~V}$ for $2 \mathrm{~h}$, dried down, and exposed to film overnight (Kodak, X-OMAT XAR 5).

Delivery of Antisense Oligonucleotides into 171-CAT Cells. Confluent 171-CAT cells were split 1:10 the day prior to transfection. Four hours prior to the addition of complex, the growth media was changed to DMEM, $10 \%$ heat-inactivated calf serum $\left(68^{\circ} \mathrm{C}, 1 \mathrm{~h}\right)$. $1 \%$ penicillin-streptomycin, and $1 \mathrm{mM} \mathrm{CaCl}_{2}$. Oligonucleotide-containing complexes were formed using the following protocol: The 
oligonucleotide-to-conjugate ratios were varied from $0: 1$ to $10: 1$ (mass ratio). The AsOR-poly(L-lysine) conjugate was diluted to an appropriate concentration in $0.15 \mathrm{M}$

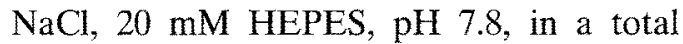
volume of $500 \mu \mathrm{l}$. The oligonucleotide was resuspended in $10 \mathrm{mM}$ Tris- $\mathrm{HCl}, 1 \mathrm{mM}$ EDTA, pH 7.4. A predetermined amount of oligonucleotide was then transferred to a solution of $0.15 \mathrm{M} \mathrm{NaCl}, 20 \mathrm{mM}$ HEPES, $\mathrm{pH}$ 7.8 in a final volume of $500 \mu \mathrm{l}$. The oligonucleotide and conjugate preparations were then mixed together for a final volume of $1 \mathrm{ml}$, gently vortexed, incubated at room temperature for $30 \mathrm{~min}$, and filtered through a $0.45 \mu \mathrm{m}$ filter prior to its addition to the 171 cells. The complex $(1 \mathrm{ml})$ was added directly to $4 \mathrm{ml}$ of the DMEM, $10 \%$ heat-inactivated calf serum, $1 \%$ penicillin-streptomycin, and $1 \mathrm{mM} \mathrm{CaCl}_{2}$ in the presence of $50 \mu \mathrm{M}$ chloroquine (Sigma). Cells were incubated in the presence of complex for $24 \mathrm{~h}$ and then analyzed for CAT activity by indirect immunofluorescence and enzyme assay of lysates.

Functionality of Oligonucleotide Molecular Conjugates. In an attempt to examine the effectiveness of the oligonucleotide toroids, the incorporation of labeled oligonucleotide into tissue culture cells was assessed in the context of free oligonucleotide versus complexed oligonucleotide. For this analysis, $500 \mathrm{ng}$ of the 18 -mer oligonucleotide was end-labeled with $\left[\gamma^{-32} \mathrm{P}\right]$ ATP $(3000 \mathrm{Ci} / \mathrm{mol}$, NEN-DuPont) using T4 polynucleotide kinase (Boehringer Mannheim Biochemical). A total of $1 \times 10^{6} \mathrm{cpm}$ of purified oligonucleotide $(100 \mathrm{ng})$ was mixed with excess unlabeled oligonucleotide $(100 \mu \mathrm{g})$ to efficiently form toroids when the DNA was mixed with conjugate at a 5:1 ratio. An equivalent amount of free oligonucleotide was prepared but not complexed to conjugate. Both 171 and $3 T 3$ cells were split to a density of $5 \times$ $10^{5}$ cells in a $60-\mathrm{mm}$ tissue culture dish in DMEM, $10 \%$ heat-inactivated calf serum, $1 \%$ penicillin-streptomycin, and $1 \mathrm{mM} \mathrm{CaCl}$.
Four hours prior to the addition of oligonucleotide, the media on the cells was replaced with fresh media. The cells were then incubated with the free and complexed oligonucleotide samples over a 3-h time period with samples removed at predetermined intervals of $0,15,30,60,120$, and 180 min. For each time point, the cells were trypsinized off the dish, washed twice in PBS, and then incubated with DNase ( 1 unit $/ \mu \mathrm{g}$ ) for $1 \mathrm{~h}$ at $37^{\circ} \mathrm{C}$. The samples were then pelleted in a microfuge at $4^{\circ} \mathrm{C}$ for $5 \mathrm{~min}$, washed three times in PBS, and finally analyzed by scintillation counting.

Chloramphenicol Acetyltransferase Assays. The net inhibition of CAT activity in the cell population was estimated by performing enzyme assays of cell lysates. The cells were washed twice in PBS, and scraped from the plate in $1 \mathrm{ml}$ of TNE $(0.04 \mathrm{M}$ Tris $\mathrm{HCl}$, pH 7.4, $1 \mathrm{mM}$ EDTA, $0.15 \mathrm{M} \mathrm{NaCl}$ ) and placed in microfuge tubes and stored on ice. The cells were pelleted in a microfuge for 3 $\min$ at $4^{\circ} \mathrm{C}$, the supernatant aspirated, and the cell pellet frozen at $-20^{\circ} \mathrm{C}$. The cell pellets were resuspended in $100 \mu \mathrm{l}$ of $0.25 \mathrm{M}$ Tris $\mathrm{HCl}, \mathrm{pH} 7.8$. The cells were frozen in a dry ice-ethanol bath for $5 \mathrm{~min}$ and immediately placed at $37^{\circ} \mathrm{C}$ for $5 \mathrm{~min}$. The freezethawing was repeated two additional times to generate the cell lysate. Protein concentration was assayed by performing a Bradford protein assay. Cell extract $(20 \mu \mathrm{g})$ was assayed for CAT activity in the presence of $50 \mu \mathrm{Ci}\left[{ }^{14} \mathrm{C}\right]$ chloramphenicol (Amersham), $0.25 \mathrm{M}$ Tris $\mathrm{HCl}, \mathrm{pH} 7.8,0.5 \mathrm{mM}$ acetyl-CoA (Pharmacia) at $37^{\circ} \mathrm{C}$ for $30 \mathrm{~min}$. Reactions products were extracted in $1 \mathrm{ml}$ ethyl acetate, dried down in a speed-vac, resuspended in 30 $\mu l$ ethyl acetate, and spotted onto thin-layer chromatography plates (Kodak, Chromagram). Chromatography was performed in chloroform-methanol $(19: 1, \mathrm{v} / \mathrm{v})$. CAT assays were analyzed and quantified on a Betagen scanner.

Indirect Immunofluorescent Detection of $C A T$. The efficiency of delivery of antisense 
oligonucleotides by the complexes was studied at the cellular level using a rabbit polyclonal antibody generated against CAT $\left(5^{\prime}-3^{\prime}\right)$. The transfected cells were grown and transfected on glass cover slips for this analysis. After $24 \mathrm{~h}$ in the presence of complex, the cells were washed twice in phosphate-buffered saline (PBS) and fixed in methanol for $10 \mathrm{~min}$ on ice. Cover slips were subsequently washed in PBS and incubated in a 1:100 dilution of CAT antibody for 30 $\min$ at $37^{\circ} \mathrm{C}$. The primary antibody was detected by incubating cells in FITCconjugated goat anti-rabbit $\operatorname{IgG}(1: 200)$ for 30 min at $37^{\circ} \mathrm{C}$. After washing in PBS, the cover slips were mounted in Citifluor mounting media (Citifluor LTD) and examined using a Microphot-FXA microscope (Nikon),

Electron Microscopy. Solutions of complex were incubated on collodion-carboncoated grids at room temperature. Excess solution was removed by capillary action and the samples were negatively stained by incubation in $2 \%$ uranyl magnesium acetate. At least two grids were examined for each complex sample using a Phillips CM-10 transmission electron microscope. All structurally defined complex macromolecules were documented by photomicrographs.

\section{RESULTS}

Binding of oligonucleotide to conjugate was assessed by a simple electrophoretic assay in which the products of the DNAprotein complex formation were electrophoresed through a nondenaturing agarose gel. Increasing amounts of conjugate $(0-1 \mu \mathrm{g})$ were added to a mixture of tracer ${ }^{32} \mathrm{P}$ end-labeled oligonucleotide ( $1 \mathrm{ng}$ ) and unlabeled oligonucleotide (99 ng). Autoradiography of a typical experiment is presented in Fig. 1. Free oligonucleotide migrates far into the gel while complexed oligonucleotide is markedly retarded. Increasing the conjugateto-oligonucleotide ratio to $5: 1$ leads to

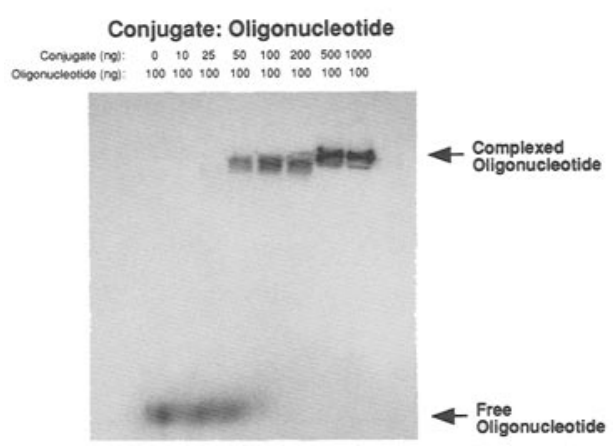

Fig. 1. Gel retardation assay of free and complexed ${ }^{32} \mathrm{p}$ end-labeled oligonucleotide. The 18-base CAT antisense oligonucleotide was end-labeled with $\left[\gamma^{-32} \mathrm{P}\right] \mathrm{ATP}$ using T4 polynucleotide kinase. A tracer amount of labeled oligonucleotide (1 $\mathrm{ng}$ ) and excess unlabeled oligonucleotide $(99 \mathrm{ng}$ ) were mixed in a $25 \mu$ of $0.15 \mathrm{M}$ $\mathrm{NaCl}, 20 \mathrm{mM}$ HEPES, pH 7.8, and incubated with 0,10 , $25,50,100,200,500$, and $1000 \mathrm{ng}$ of AsOR-polv(Llysine) conjugate also in $25 \mu$ (of $0.15 \mathrm{M} \mathrm{NaCl}, 20 \mathrm{mM}$ HEPES, pH 7.8 , incubated for $30 \mathrm{~min}$ at room temperature, and then electrophoresed through a $1.5 \%$ agarose gel. The gel was dried and exposed to fim overnight. The amount of conjugate and oligonucleotide in each sample is indicated above and the state of the oligonucleotide is indicated by the arrows (complexed oligonucleotide vs. free oligonucleotide).

complete formation of complex that does not electrophorese out of the well.

In an attempt to define the structure of the resulting DNA-protein complex, the products of reactions analyzed in Fig. 1 were further characterized by electron microscopy using negative staining. Complex formed at mass ratios of conjugate-DNA less than or equal to 2:1 revealed no specific macromolecular structures. As shown in Fig. 2, when the mass ratio of conjugate to oligonucleotide was increased to $5: 1$, donutlike structures with diameters ranging from 50 to $150 \mathrm{~nm}$ were consistently observed. Similar structures, called toroids, have been previously observed as a result of binding polycations to high-molecular-weight DNA (30).

Functionality of the AsOR-poly(Llysine)-oligonucleotide complexes was assessed using a mouse fibroblast cell line genetically modified to stably express the asialoglycoprotein (ASGP) receptor and CAT. The cell line used in the present study 


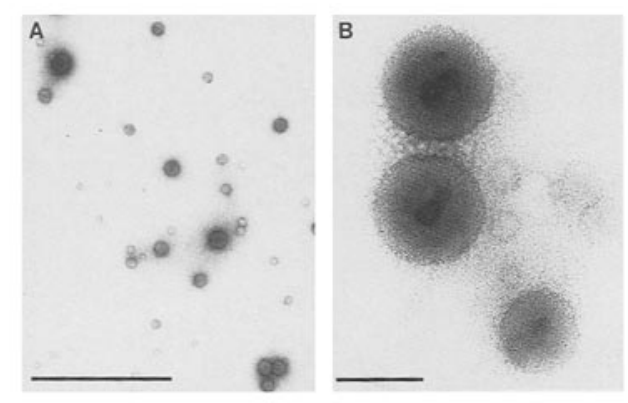

Fig. 2. Electron microscopic analysis of oligonucleotideconjugate macromolecular structure. The same samples used for gel retardation assay were analyzed by electron microscopy. (A) A 40,000 $\times$ magnification of negatively stained toroids observed by formation of complex with $100 \mathrm{ng}$ oligonucleotide and $500 \mathrm{ng}$ conjugate, size bar represents $1 \mu \mathrm{m}$. (B) A $219,000 \times$ magnification of negatively stained oligonucleotide derived toroids, size bar represents $100 \mathrm{~nm}$.

is called 171 . Since the 171 cells were directly derived from NIH 3 T3 cells, this provided the unique opportunity to retain a genetic control in terms of ASGP receptor expression. The role of the ASGP receptor in the mediation of uptake of molecular conjugates can be assessed by direct comparison of 171 and $3 \mathrm{~T} 3$ cells that have been engineered to express CAT.

The effectiveness of molecular conjugates for delivery of oligonucleotides into eukaryotic cells was assessed by monitoring uptake of free and complexed ${ }^{32} \mathrm{P}$ endlabeled oligonucleotide. Figure 3 demonstrates the results of incorporation of free and complexed oligonucleotide into 171 and $3 T 3$ cells. In the presence of free oligonucleotide, both cell lines showed a timedependent increase in the label associated with the cells pellet over the time period. However, when the cells are incubated in presence of oligonucleotide toroids, a timedependent incorporation of oligonucleotide was only observed in the 171 cells. Additionally, the amount of label associated with the cell pellet was threefold greater in the 171 cells when it was in the context of a toroid as opposed to free oligonucleotide.

The 171 cell line was exposed to increasing concentrations of oligonucleotide complexes (DNA ranging from 0 to $100 \mu \mathrm{g}$ in complexes formed at a conjugate to oligonucleotide ratio of 5:1) for $24 \mathrm{~h}$ in the presence of chloroquine. The cells were analyzed for changes in expression of CAT by simultaneous assays for enzymatic activity in cell lysates and indirect immunofluorescence to detect protein at a cellular level. Figure 4A summarizes the effect of increasing concentrations of oligonucleotide complex on CAT activity in whole cell lysate. Increasing the

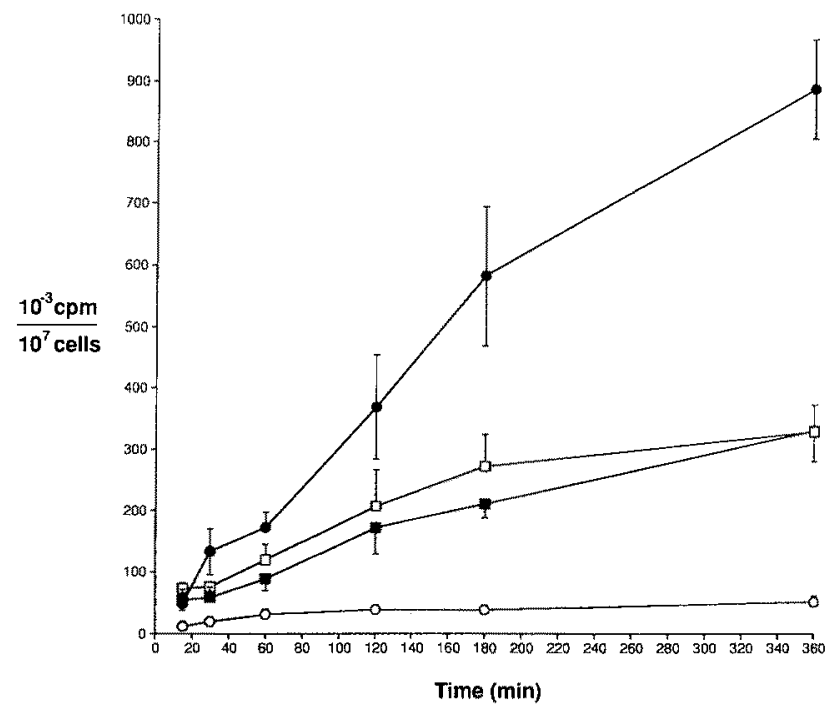

Fig. 3. Comparison of uptake of ${ }^{32} \mathrm{P}$-endlabeled oligonucleotide into 171 and 3T3 cells. One $\times 10^{6} \mathrm{cpm}$ of end-labeled oligonucleotide (100 ng) was incubated on $5 \times$ $10^{5}$ cells in both free and complexed forms for variable lengths of time from 0 min up to $360 \mathrm{~min}$. The average amount of uptake from three experiments is represented graphically as follows: open circles, 3T3 cells + complexed oligonucleotide; open squares, $3 \mathrm{~T} 3$ cells + free oligonucleotide; closed squares, 171 cells + free oligonucleotide; and closed circles, 171 cells + complexed oligonucleotide. 
Fig. 4. Analysis of CAT gene expression in 171 cells transfected with oligonucleotide-AsOR-poly(L-lysine) complexes, Complexes containing increasing amounts of CAT antisense oligonucleotide were formed and incubated on the cells for a 24 -h period. Control experiments of competition of uptake by incubation of complex in the presence of a molar excess of free AsOR (1 mg) and formation of complex with an irrelevant HBV oligonucleotide were also performed. The genetic negative control 3T3 cells expressing CAT also demonstrated no inhibition of CAT' activity when incubated in the presence of oligonucleotide toroids. After the incubation, the cells were harvested and analyzed using both an enzyme assay and indirect immunofluorescence. Cell lysates were prepared by freeze-thawing. (A) Results of CAT enzyme assays on $20 \mu \mathrm{g}$ of cell lysate depicted as percent inhibition of CAT activity. (B) Results of analysis for CAT protein by indirect immunoffuorescence with a rabbit polyclonal antibody to the CAT protein. More than 500 cells were analyzed for each duplicate sample and only those scoring completely negative for immunofluorescence were counted.

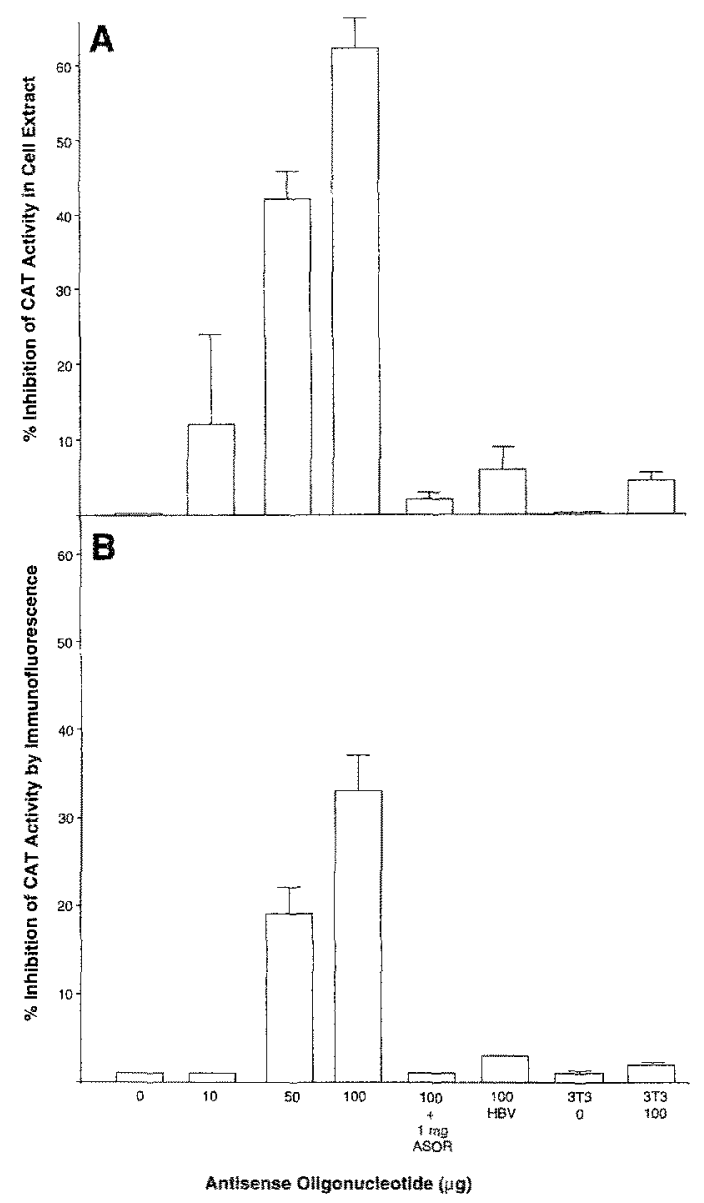

antisense function by estimating the cellspecific expression of CAT protein using immunohistochemistry. Exposure of the cells to increasing concentrations of CAT oligonucleotide toroids led to the appearance of a subpopulation of cells completely void of CAT protein. A maximum of $33 \pm 4 \%$ (mean $\pm 1 S D, N \geq 3$ ) nonexpressing cells was achieved with $100 \mu \mathrm{g}$ of oligonucleotide in toroids. An example of this analysis is shown in Fig. 5. 171 cells transfected with conjugate alone showed bright fluorescence in $>95 \%$ of the cells (panels A and B), while transfection with CAT oligonucleotide toroids was associated with a substantial reduction of fluorescence in a subpopulation of the cells (panels C and D). No alterations 

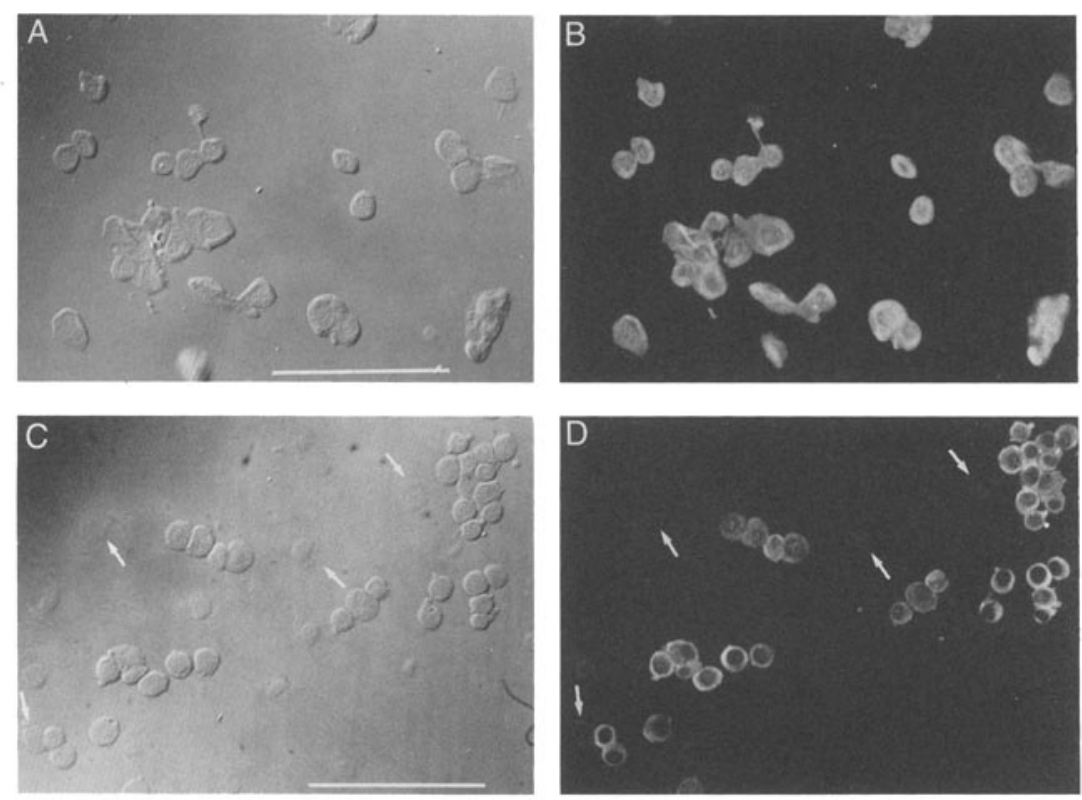

Fig. 5. An example of CAT immunohistochemistry in 171 cells. Cells were fixed for $10 \mathrm{~min}$ in methanol and washed with phosphate-buffered saline (PBS). CAT protein was detected as described in Materials and Methods. (A) Control cells transfected with $500 \mu \mathrm{g}$ of AsOR-poly(L-lysine) conjugate alone viewed under Nomarski optics. (B) Immunofluorescent detection of CAT in conjugate-transfected cells. (C) Nomarski optic view of cells transfected with oligonucleotide containing complexes $(100 \mu \mathrm{g}$ oligonucleotide and $500 \mu \mathrm{g}$ conjugate). (D) Immunofluorescent detection of CAT protein in oligonucleotide complex transfected cells. Cells lacking staining are indicated by arrows. Size bar represents $160 \mu \mathrm{m}$.

in the immunofluorescent staining pattern was observed in the $3 \mathrm{~T} 3 \mathrm{CAT}$ cell line. The specificity of antisense inhibition was again confirmed by the absence of an effect with toroids coincubated with excess AsOR or toroids containing HBV antisense oligonucleotides.

Having demonstrated the function of antisense-containing toroids, conditions were determined to optimize their activity in vitro. Complexes formed with different ratios of conjugate and DNA were characterized with respect to inhibition of CAT activity in 171 cells (Fig. 6). Complexes formed with proteinto-DNA mass ratios of up to 2:1 showed insignificant levels of inhibition of CAT expression, while complexes formed at the 5:1 and 10:1 mass ratios showed a marked increase in the levels of inhibition of CAT activity.

In order to more fully understand the effectiveness of the oligonucleotide complexes as a delivery system, 171 CAT cells were incubated in the presence of increasing concentrations of naked oligonucleotides up to a maximum of $30 \mu \mathrm{M}(850 \mu \mathrm{g} / 5 \mathrm{ml})$. As shown in Fig. 7, the level of inhibition of CAT expression is proportional to the concentration of oligonucleotide with $62 \pm$ $4 \%$ (mean $\pm 1 S D, N \geq 3$ ) inhibition achieved with free oligonucleotide. Analysis of these cells by indirect immunofluorescence for the CAT protein revealed a broad range of residual CAT protein, but showed only a few cells in which CAT expression was totally inhibited ( $\sim 5 \%$, data not shown).

\section{DISCUSSION}

A significant problem with in vivo applications of antisense oligonucleotide technology is the difficulty associated with 
Fig. 6. CAT enzyme analysis of cells transfected with oligonucleotide complexes formed with varying conjugate concentrations. A constant $100 \mu \mathrm{g}$ of oligonucleotide was incubated with varying amounts of conjugate $(0,10,50,100,200,500$, and $1000 \mu \mathrm{g})$ in a $1-\mathrm{ml}$ final volume, as previously described. 171 cells were transfected for $24 \mathrm{~h}$ and cell lysates prepared by freeze-thaw fracture; $20 \mu \mathrm{g}$ of cell lysate was used per assay. Data are represented as percent inhibition of CAT activity.

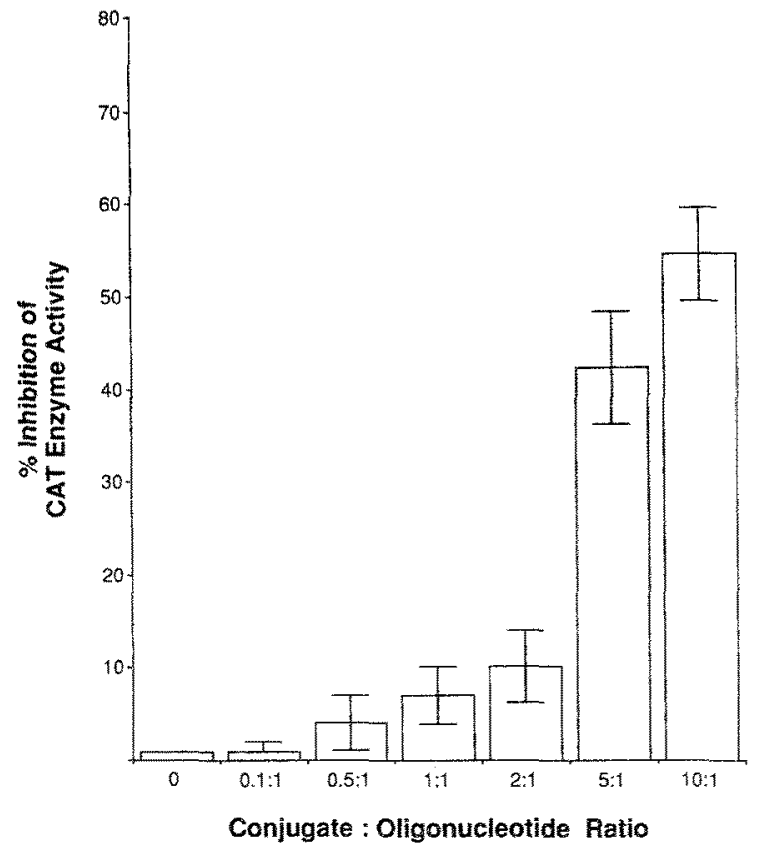

that molecular conjugates can effectively be utilized as an alternative approach to deliver oligonucleotides into cells.

Several approaches have been developed for delivery of oligonucleotides in vitro. The standard approach involves incubating
Fig. 7. CAT enzyme activity analysis of cells incubated in the presence of uncomplexed oligonucleotide. 171 cells were incubated with varying amounts of oligonucleotide $0,250,425,850 \mu \mathrm{g}$ in DMEM, $10 \%$ heat inactivated calf serum, $1 \%$ penicillin-streptomycin, $1 \mathrm{mM} \mathrm{CaCl}$ for $24 \mathrm{~h}$. Cells were harvested and lysed as previously described; $20 \mu \mathrm{g}$ of cell lysate was used per assay. Data are represented as percent inhibition of CAT activity.

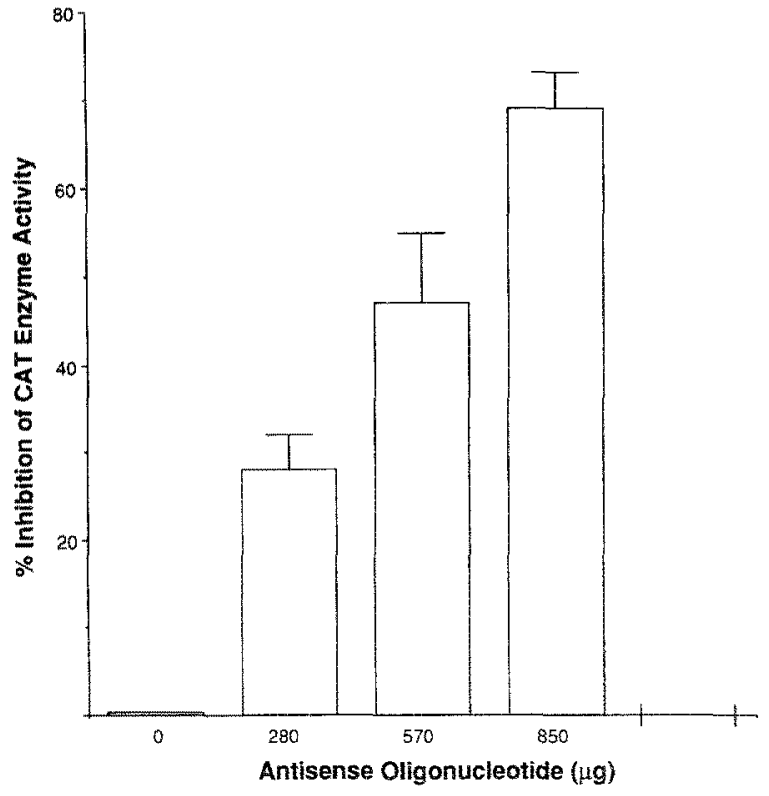


the naked oligonucleotides in the culture media. The oligonucleotide is transported into the cell by active transport mechanisms. The drawback of this approach is that milligram quantities of oligonucleotide are often required to observe inhibitory effects. Direct microinjection of oligonucleotides into cells has been successfully utilized to deliver large quantities of oligonucleotide to cells (31). However, this approach is severely limited by the inability to inject oligonucleotide into a large number of cells. Lastly, liposome-mediated delivery of oligonucleotides has been used as a moderately successful nonspecific approach for delivery (32).

The method described in this report is based on the stable and nondestructive interactions of phosphorothioate oligonucleotides and the AsOR-poly(L-lysine) conjugates. Under appropriate conditions mixtures of oligonucleotide and conjugate form a stable toroidal structure easily visualized under EM. This structure resembles a donut of $50-150 \mathrm{~nm}$ in diameter. Our studies indicate that the toroidal structure is necessary to achieve efficient antisense delivery. The toroids formed with the oligonucleotide have the same range of diameter as those formed with plasmid DNA, indicating that there may be a standard size range for the toroids, which would provide a great deal of continuity for the use of molecular conjugates for gene delivery (data not shown).

An important factor in the use of molecular conjugates for the delivery of antisense oligonucleotides is the ability to significantly reduce gene expression with substantially less oligonucleotide. The delivery of oligonucleotides in the context of a toroid appears to be much more efficient than uptake by the active transport mechanism of free oligonucleotides, as demonstrated by the incorporation of ${ }^{32} \mathrm{P}$-labeled oligonucleotide in the context of a toroid. Fivefold less oligonucleotide was required to achieve $50 \%$ inhibition of CAT when it is delivered in the context of a toroid. It is also important to note that when oligonucleotides were delivered by molecular conjugates, there was a significant subpopulation of cells that lacked any detectable CAT activity. Cells incubated with noncomplexed oligonucleotide showed a reduction in CAT activity, but when examined by indirect immunoffuorescence $>95 \%$ of the cells retained some levels of CAT protein. The improved delivery of oligonucleotides by molecular conjugates marks a significant improvement in the effectiveness of antisense oligonucleotides for the inhibition of gene expression.

Another significant advantage of molecular complexes is the potential for the cell-specific targeting of oligonucleotide delivery. The uptake of the AsOR-poly(L-lysine)oligonucleotide complexes is clearly mediated by the ASGP receptor found on the 171 cells. The fact that a preselected receptor ligand is utilized in the formation of the complexes should permit them to be targeted to a specific population or subset of cells within a heterogenous population. Providing that the complexes are stable in vivo, this specificity should provide a viable approach to efficiently deliver large amounts of the oligonucleotide precisely to a selected target organ.

In this report, we summarize the development of a system for the efficient and targeted delivery of antisense oligonucleotides to eukaryotic cells. The use of molecular conjugates for the delivery of oligonucleotides may prove to be a significant advancement in the area of antisense oligonucleotide derived therapies. Experiments are currently in progress to examine the effectiveness of molecular conjugates in vivo.

\section{ACKNOWLEDGMENTS}

We wish to acknowledge J. Petryniak for help in preparation of the conjugate and $L$. Austin and E. Allen for assistance with the electron microscopic analysis of the conjugates. This work was supported by the 
Howard Hughes Medical Institute, grants from the NIH (J.M.W.), and a Judith Graham Pool Postgraduate Research Fellowship from the National Hemophilia Foundation (F.K.A.).

\section{LITERATURE CITED}

1. Mizuno, T., Chou, M.-Y., and Inouye, M. (1984). Proc. Natl. Acad. Sci. U.S.A. 81:1966-1970.

2. Heywood, S.M. (1986). Nucleic Acids Res. 14:67716772.

3. Zamecnik, P.C., and Stephenson, M.L. (1978). Proc. Natl. Acad. Sci. U.S.A. 75:280-284.

4. Stephenson, M.L., and Zamencik, P.C. (1978). Proc. Natl. Acad. Sci. U.S.A. 75:285-288.

5. Zamencik, P.C., Goodchild, J., Taguchi, Y., and Sarin, P.S. (1986). Proc. Natl. Acad. Sci, U.S.A. $83: 4143-4146$.

6. Zerial, A., Thoung, N.T., and Helene, C. (1987). Nucleic Acids Res. 15:9909-9919.

7. Stein, C., Mori, K. Loke, S, Subasinghe, C, Shinozuka, K., Cohen, J., and Neckers, L. (1988). Gene 72:333-341.

8. Yakubov, L., Deeva, E., Zarytova, V., Ivanova, E., Ryte, A., Yurchenko, L, and Vlassov, V. (1989). Proc. Natl. Acad. Sci. U.S.A. 86:6454-6458.

9. Marcus Sekura, C.J., Woerner, A.M., Shinozuka, K., Zon, G., and Quinnan, G.V. (1987). Nucleic Acids Res. 15:5749-5763.

10. Stec, W.J., Zon, G., Egan, W., and Stec, B. (1984). J. Am. Chem. Soc. 106:6077-6079.

11. LaPlanche, L.A., James, T.L., Powell, C., Wilson, W.D., Uznanski, B., Stec, W.J., Summers, M.E., and Zon, G. (1986). Nucleic Acids Res. 14:90819093.

12. Miller, P.S. (1989). In Oligonucleotidedeoxyribonucleotides. Antisense Inhibitors of Gene Expression, (ed.) Cohen, J. (CRC press, Boca Raton, Florida), pp. 79-95.

13. Miller, P.S. (1991). Biotechnology 9:358-362.

14. Miller, P.S., McParland, K.B., Jayaraman, K., and Ts'o, P.O.P. (1981). Biochemistry 20:1874-1880.
15. Eppstein, D.A., Schryver, B.B., and Marsh, Y.V. (1986).J. Biol. Chem. 261:5999-6003.

16. Miller, P.S., Barrett, J.C., and Ts'o, P.O.P. (1974). Biochemistry 13:4887-4896.

17. Doel, M.T., Jones, A.S., and Taylor, N. (1969). Tetrahedron Lett. 27:2285-2288.

18. Agris, C.H., Blake, K.R., Miller, P.S., Reddy, M.P., and Ts'o, P.O.P. (1986). Biochemistry 25:6268-6275 .

19. Zaia, J.J., Rossi, J.J., Murakawa, G.J., Spallone, P.A., Stephens, D.A., Kaplan, R.E., Eritja, R., Wallace, R.B., and Cantin, E.M. (1988). J. Virol. 62:3914-3917.

20. Chang, L.-J., and Stoltzfus, C.M. (1987). J. Virol. 61:921-924.

21. Wu, G.Y., and Wu, C.H. (1987). J. Biol. Chem. 262:4429-4432

22. Wu, G.Y., and Wu, C.H. (1988). Biochemistry 27:887-892.

23. Wu, C.H., Wilson, J.M., and Wu, G.Y. (1989). $J$. Biol. Chem. 264:16985-16987.

24. Curiel, D.T., Agarawl, S., Wagner, E., and Cotten, M. (1991). Proc. Natl. Acad. Sci. U.S.A. 88:88508854.

25. Wagner, E., Zenke, M., Cotten, M., Beug, H., and Birnstiel, M.L. (1990), Proc. Nati. Acad. Sci. U.S.A. 87:3410-3414.

26. Wilson, J.M., Grossman, M., Wu, C.H., Chowdhury, N.R., Wu, G.Y., and Chowdhury, J.R. (1992). J. Biol. Chem. 267:963-967.

27. Shia, M.A., and Lodish, H.F. (1989). Proc. Natt. Acad. Sci. U.S.A. 86:1158-1162.

28. Hartman, S.C., and Mulligan, R.C. (1988). Proc. Natl. Acad. Sci. U.S.A. 85:8047-8051.

29. Price, J., Turner, D., and Cepko, C. (1987). Proc. Natl Acad. Sci. U.S.A. 84:156-160.

30. Haynes, M., Grant, R.A., and Gratzer, W.B. (1970). Biochemistry 9:4410-4416.

31. Leonetti, J.P., Mechti, N., Degols, G., Gagnor, C., and Lebleu, B. (1991). Proc. Natl. Acad. Sci. U.S.A. 88:2702-2706.

32. Thierry, A.R., Rahman, A., and Ditschilo, A. (1992). In Gene Regulation, Biology of Antisense RNA and DNA, (eds.) Erickson, R.P., and Izant, J.G. (Raven Press, New York), pp. 147-161. 